
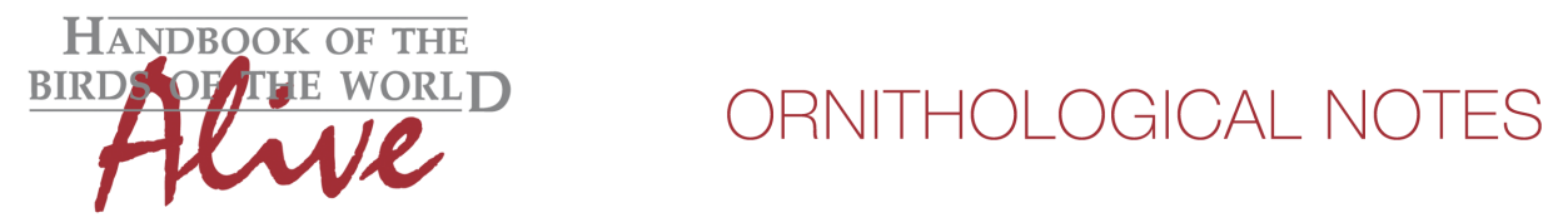

\title{
Notes on the vocalizations of Vilcabamba Thistletail (Schizoeaca vilcabambae)
}

Peter Boesman

In the following we briefly analyze and compare voice between the two races of Vilcabamba Thistletail (Schizoeaca vilcabambae). We also try to quantify the extent of any vocal differences using the criteria proposed by Tobias et al. (2010), as a support for taxonomic review. We have made use of sound recordings available on-line from Macaulay Library (ML).

As an introductory note, it should be said that voice of most if not all Thistletails is at least structurally very similar, and seemingly in this genus is not a good indicator for speciation. Song of most Thistletails is a series of gradually rising and accelerating notes changing to a descending trill (e.g. Ochre-browed Thistletails S. coryi, Mouse-coloured Thistletail S. griseomurina). Some species however seem to mainly or exclusively sing just a rising/falling trill (e.g. Eye-ringed Thistletail S. palpebralis). And some species seem to have both vocalisations (e.g. White-chinned Thistletail S. fuliginosa), and thus maybe all Thistletails do, but just the rate of delivery is different, or it is somewhat linked to subspecific taxa of that species (not investigated) (Fig. 1).

Question here is whether there is a vocal difference between the two races vilcabambae and ayacuchensis. There are no recordings on XC, but a few of both races in $\mathrm{ML}$, allowing for comparison.

All recordings of vilcabambae have the song type with slow introductory notes. All recordings of ayacuchensis have the single up and down trill (Fig 2 ). The similarity with respectively $F$. fuliginosa and $A$. palpebralis is striking.

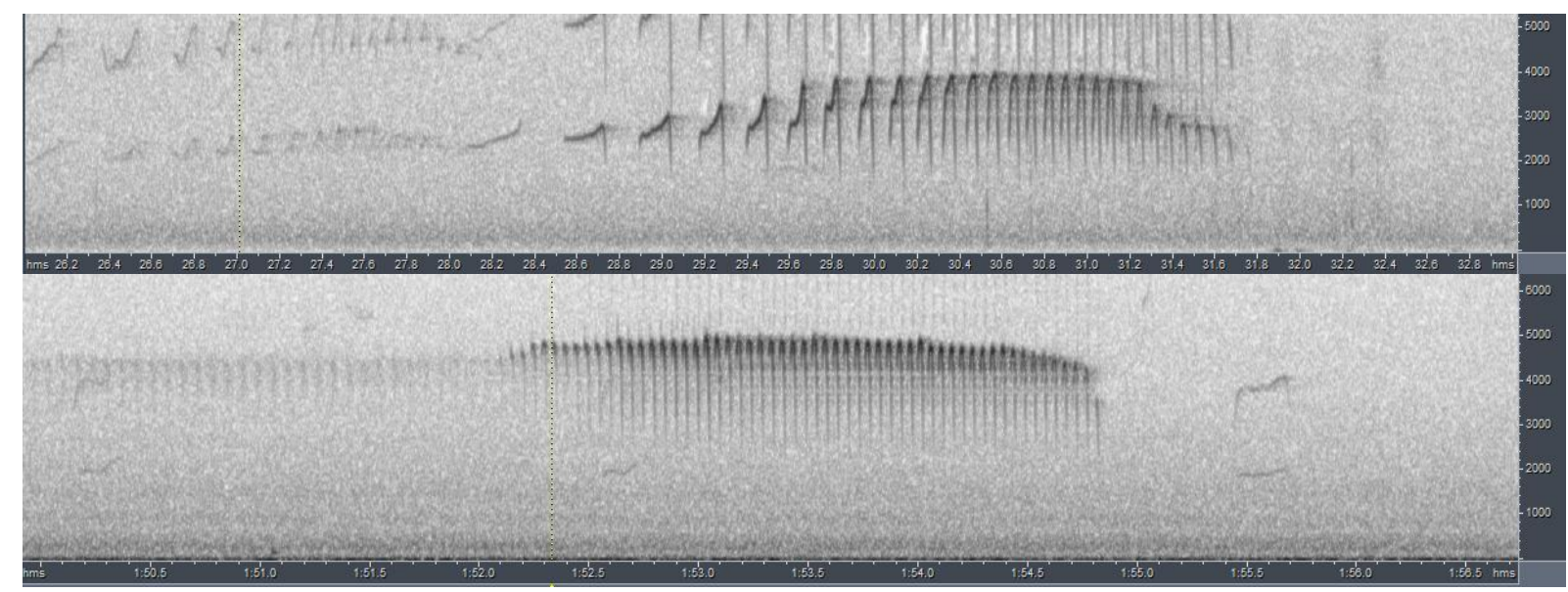

Figure 2: song of vilcabambae (top) and ayacuchensis (bottom) 


\section{HANDBOOK OF THE \\ Alve}

\section{ORNITHOLOGICAL NOTES}

\section{White-chinned Thistletail}

A. fuliginosa fumigata

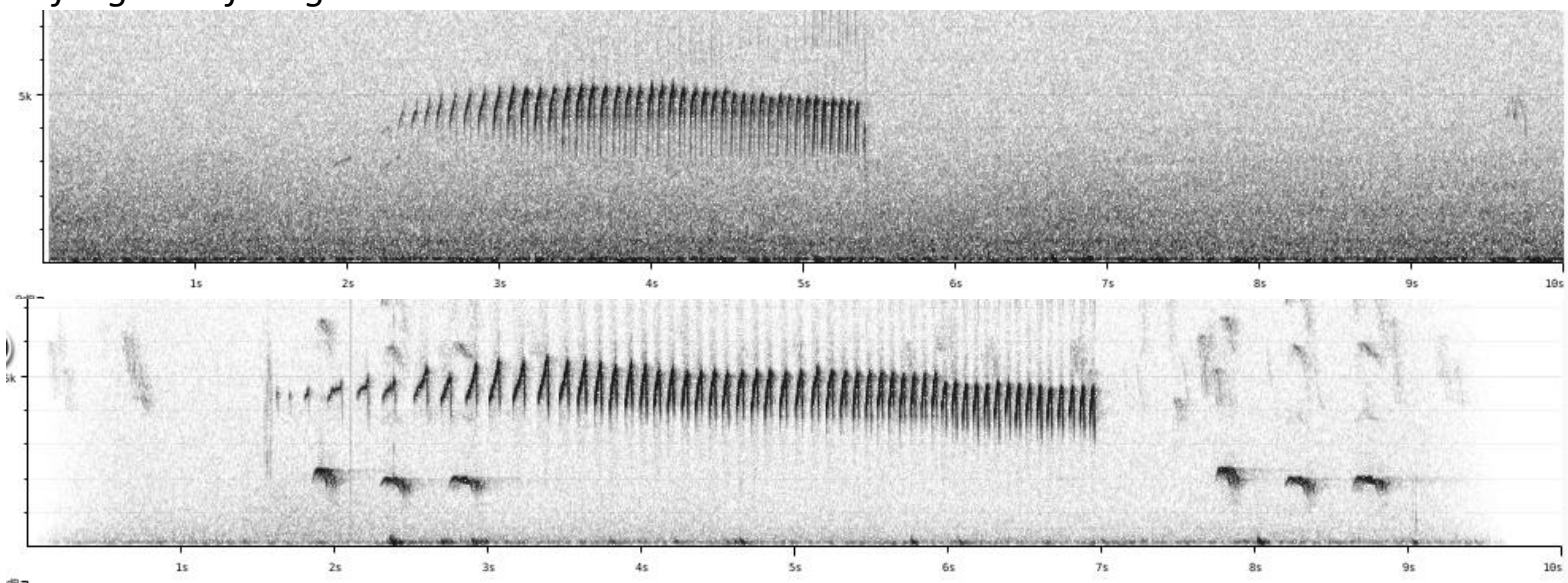

A.f.fuliginosa

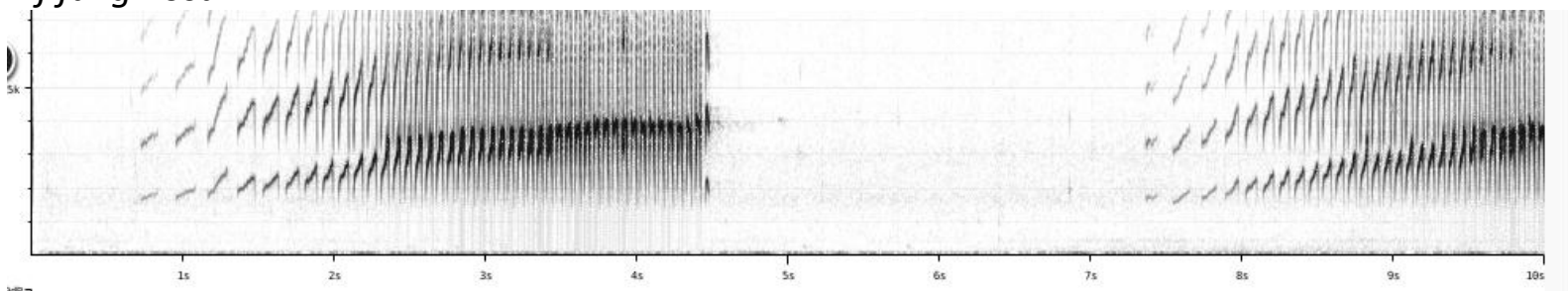

Eye-ringed Thistle-tail A. palpebralis

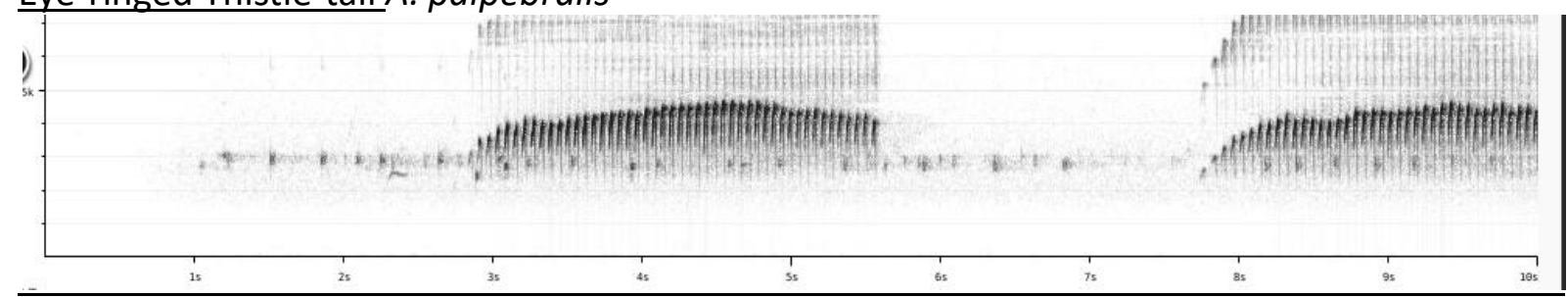

Black-throated thistle-tail $A$. harterti

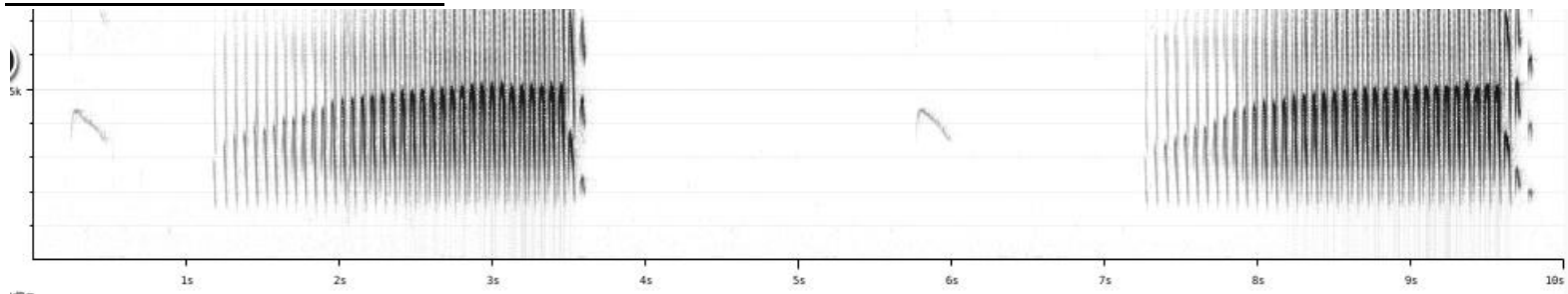

Mouse-coloured Thistle-tail A. griseomurina

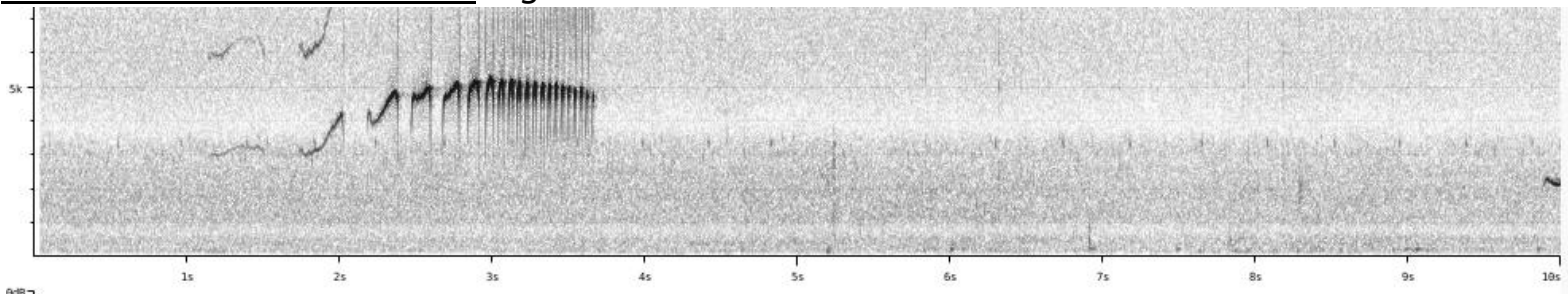

Figure 1: Examples of song of different Thistletail species 

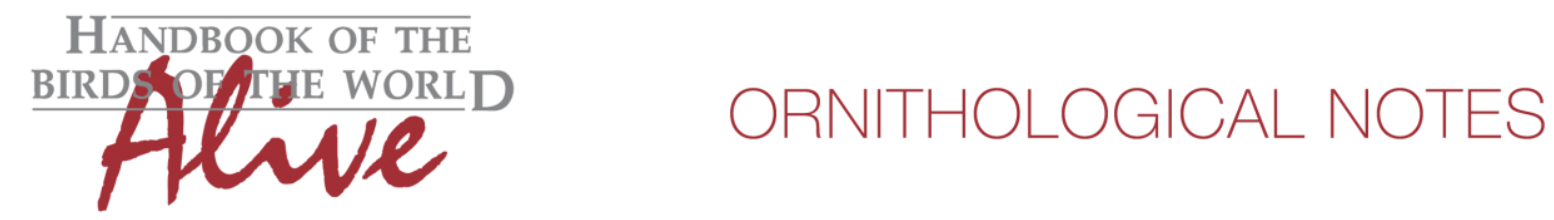

This may thus seem a clear-cut case, if only we could be sure that these (few) recordings are indeed representative, and not just a coincidence that one race was singing one song type and the other race the other type. This seems unlikely but of course not impossible, as there are only 3 available recordings of song of ayacuchensis from the same place (but obviously, given the tiny range of this taxon one can't expect many different places...). HBW describes song of e.g. Eye-ringed Thistletail S. palpebralis exclusively as a trill, so it might well be that some species only sing the trilled song and other species only the accelerating song.

Hosner et al. (2015) already noted the striking vocal difference of both races (based on the same available recordings), but failed to mention that some species do sing both song types, which calls for considerable caution when assessing vocal difference to avoid oversimplification.

Strict application of Tobias criteria would lead to high scores for vocal difference based on e.g. note length (3), \# of notes ( 3 ) etc., but I would suggest to score song difference as moderate (score 2 ) given the larger context of Thistetail vocalizations and the uncertainty about the exclusive use of a single song type.

To search for further evidence of possible vocal differences, one can also investigate call notes. We measured the following:

vilcabambae $(n=7)$ :

max. freq. : $3500-5150 \mathrm{~Hz}$

note length: $0.27-0.38 \mathrm{~s}$

ayacuchensis $(n=3)$ :

max. freq. : $5300-5700 \mathrm{~Hz}$

note length: $0.32-0.38 \mathrm{~s}$

Based on this notable difference (which confirms earlier findings in Hosner et al. 2015) in max. freq., this would lead to a score of 3. (However, again at least some other Thistletails share these call notes, and it would be interesting to further analyze if the combination of song and call allows to distinguish all or most present species (e.g. Eye-ringed Thistletail has a very characteristic call note).

All in all, I believe there is sufficient evidence to conclude that ayacuchensis and vilcabambae are vocally distinct.

Considering that both song and call are different, albeit less so when looking at the total 'Thistletail-picture', I would suggest to give a score of about 4.

This note was finalized on 10th January 2016, using sound recordings available on-line at that moment. We would like to thank in particular the sound recordists who placed their recordings for this species on ML: Peter Robbins, Mark Robbins, Thomas Schulenberg, Thomas Valqui and John Weske. 


\section{References}

Hosner, P., Aparicio, L.E.C., Ferro-Meza, G. \& Robbins, M. (2015) Vocal and Molecular Phylogenetic Evidence for Recognition of a Thistletail Species (Furnariidae: Asthenes ) Endemic to the Elfin Forests of Ayacucho, Peru. Wilson Journal 127(4): 724-730.

Tobias, J.A., Seddon, N., Spottiswoode, C.N., Pilgrim, J.D., Fishpool, L.D.C. \& Collar, N.J. (2010). Quantitative criteria for species delimitation. Ibis 152(4): 724-746.

\section{Recommended citation}

Boesman, P. (2016). Notes on the vocalizations of Vilcabamba Thistletail (Schizoeaca vilcabambae). HBW Alive Ornithological Note 98. In: Handbook of the Birds of the World Alive. Lynx Edicions, Barcelona. (retrieved from http://www.hbw.com/node/932003 on 20 July 2016). 